\title{
Application and Validation of Simple Isocratic HPLC-UV-DAD Method with Dual Wavelength Detection for Ivabradine Determination and Its Application in the Study of Stress Degradation
}

\author{
Joanna Nowakowska, ${ }^{1}$ Piotr Pikul, ${ }^{1,2}$ Marcin Marszał, ${ }^{3}$ and Krzesimir Ciura ${ }^{1}$ \\ ${ }^{1}$ Department of Physical Chemistry, Medical University of Gdańsk, Gdańsk, Poland \\ ${ }^{2}$ Department of Therapy Monitoring and Pharmacogenetics, Medical University of Gdańsk, Gdańsk, Poland \\ ${ }^{3}$ Department of Toxicology, Medical University of Gdańsk, Gdańsk, Poland \\ Correspondence should be addressed to Krzesimir Ciura; krzesimir.ciura@gmail.com
}

Received 5 April 2017; Accepted 10 July 2017; Published 7 August 2017

Academic Editor: Andrea Gambaro

Copyright (C) 2017 Joanna Nowakowska et al. This is an open access article distributed under the Creative Commons Attribution License, which permits unrestricted use, distribution, and reproduction in any medium, provided the original work is properly cited.

Ivabradine is a modern drug that selectively lowers the heart rate, improves cardiac energy balance, and reduces heart's demands for oxygen and energy. Due to the chemical nature of ivabradine, which absorbs light at $207 \mathrm{~nm}$ and $286 \mathrm{~nm}$, its detection was performed at two wavelengths. A Knauer C8 column was used to develop the RP-HPLC method for determination of ivabradine. The proposed method was linear from 5 to $100 \mu \mathrm{g} / \mathrm{ml}(r>0.999)$ for both wavelengths and limits of detection (LOD) and limits of quantification (LOQ) were 0.33 and $1.09 \mu \mathrm{g} / \mathrm{ml}$ for $207 \mathrm{~nm}$ and 1.19 and $3.97 \mu \mathrm{g} / \mathrm{ml}$ for $286 \mathrm{~nm}$, respectively. After validation, the investigated method was applied to a stress degradation study. Numerous degradation products were formed from ivabradine solutions through alkaline and acid hydrolysis, oxidation, and photolysis. The largest numbers of degradation products were found in the sample exposed to $24 \mathrm{~h}$ radiation and alkaline hydrolysis (eight and six products, resp.). Finally, the simple method using HPLC-UV-DAD was developed and validated. Its usefulness for the monitoring of possible degradation products was demonstrated.

\section{Introduction}

Ivabradine is a cardiac drug that belongs to the group of funny channel $\left(I_{f}\right)$ inhibitors [1]. It is the only representative of that group of drugs that has been introduced for the treatment of chronic coronary artery disease and chronic heart failure $[2,3]$. This molecule selectively blocks the $f$ channel, which is responsible for initiation of the diastolic depolarisation phase of the action potential, resulting in slower increase of the pacemaker current. The slower the increase of pacemaker current, the lower the heart rate. Because of this mechanism, ivabradine has been effectively introduced into cardiac therapeutics. $I_{f}$ channels, also called hyperpolarisation-activated cyclic nucleotide-gated (HCN) channels, are intermembrane structures that act as nonselective ligand-gated cation channels. There are four known HCN channels, labelled from 1 to 4 . HCN4 is the most widespread isoform in the sinoatrial node and is responsible for diastolic depolarisation [4-6].

The drug is orally administrated in doses of 5 or $7.5 \mathrm{mg}$ as its hydrochloride salt. It should also be emphasised that ivabradine (brand name Procoralan) is produced by only one company, Servier. For this reason, ivabradine does not have a pharmacopoeia monograph. As a consequence, the reference method for ivabradine determination is not universally accepted. Ivabradine often appears in the scientific literature, but a monograph describing the method of its determination is still not sufficient. Studies about the application of thin layer chromatography (TLC) to its analysis have been published in the last five years $[7,8]$. The most important HPLC work was carried out by Klippert et al. [9, 10]. They applied fluorescence and mass spectroscopy as detectors but neither method of detection is so widespread as UV-DAD detection. 
Stress testing of the drug substance may help in identification of probable degradation products, which can lead to a better understanding of the degradation pathways and the internal stability of the molecule. Our previous work presented forced degradation studies of ivabradine [11]. The analyses were carried out with HPLC-MS. Other researchers have also presented investigations of ivabradine degradation products. Mass spectroscopy detection has been widely used in identification of ivabradine $[12,13]$. Patel et al. have studied ivabradine degradation products with Q-TOF LC/MS. During the conducted tests, only five degradation products were identified from acid degradation [14]. Degradation products of ivabradine have also been examined with the use of TLC [15]. HPLC with UV-Vis detection has been used to establish degradation products of ivabradine, but the authors obtained from its acid hydrolysis only one degradation product [16]. The main purpose of this work is to develop and validate a simple method for the quantitative determination of ivabradine, based on HPLC-UV-DAD, and to show its applicability for detection of degradation products and possible impurities.

\section{Experimental}

2.1. Instrumentation. The UV-Vis diode array detector UVD340S, pump P 580, column thermostat STH 585, autosampler injector ASI-100, and operating system Chromeleon, all from Dionex Corporation (Sunnyvale, CA, USA), were used to perform chromatographic analysis operated by the Chromeleon chromatography management system. The Knauer C8 column $(5 \mu \mathrm{m}, 250 \mathrm{~mm} \times 4.6 \mathrm{~mm}$ ID) was used during this study.

Degradation studies were carried out using Thermostat CC2-K6 from Huber (Offenburg, Germany); photo stability studies were performed utilizing a photostability Suntest CPS+ Atlas chamber (Accelerated Tabletop Exposure Systems, Gelnhausen, Germany) with a xenon lamp.

2.2. Chemicals and Reagents. The tested ivabradine hydrochloride (purity $\geq 99 \%$ ) bulk powder was supplied by Watson International Ltd. (Kunshan, China). Acetonitrile was purchased from Sigma-Aldrich Chemical Co. (St. Louis, MO, USA); ammonium acetate, hydrochloric acid, and sodium hydroxide (analytical grade) were purchased from $\mathrm{POCH}$ (Gliwice, Poland). 30\% hydrogen peroxide was bought from J. T. Baker (Deventer, The Netherlands). Before use, water was purified by Direct-Q3 UV-R Merck Millipore system (Darmstadt, Germany).

2.3. Chromatographic Conditions. The mobile phase consisted of $40 \%$ acetonitrile and $60 \% 20 \mathrm{mmol}$ ammonium acetate aqueous solution. The isocratic flow was set at $1 \mathrm{ml} /$ min and the injection volume was $20 \mu \mathrm{l}$. The column oven was set at $40^{\circ} \mathrm{C}$ and the autosampler temperature at $4^{\circ} \mathrm{C}$. Detection of ivabradine was performed at 207 and $286 \mathrm{~nm}$. Average retention time was $8.42( \pm 0.12) \mathrm{min}$.

2.4. Method Validation. Validation was performed for two wavelengths: 207 and $286 \mathrm{~nm}$. The $207 \mathrm{~nm}$ wavelength is rarely used, due to the unstable baseline, but these studies have shown its usefulness. The specificity of the method was proved by determining peak purity for IVA in a mixture of stressed samples using HPLC-UV-DAD. To establish linearity, solution containing $1 \mathrm{mg} / \mathrm{ml}$ of IVA was diluted to six different concentrations within the range of 5-200 $\mu \mathrm{g} / \mathrm{ml}$. All samples were analysed in triplicate. The accuracy was determined by analysis of samples at three different concentrations $(10,50$, and $100 \mu \mathrm{g} / \mathrm{ml})$ in triplicate, and the recoveries of the added drug were obtained from the difference between peak areas of fortified and unfortified samples. The intraand interday precisions were determined at three different concentrations, 10,50 , and $100 \mu \mathrm{g} / \mathrm{ml}$, on the same day $(n=$ 3 ) and on 3 consecutive days $(n=9)$. The robustness of the proposed method was determined by introducing the purposeful changes in the flow rate $(0.6-0.8 \mathrm{ml} / \mathrm{min})$, column temperature $\left(30 \pm 5^{\circ} \mathrm{C}\right)$, and $\mathrm{pH}$ of mobile phase $(3.0 \pm 0.2)$, while analysing samples at three different concentrations (10, 50 , and $100 \mu \mathrm{g} / \mathrm{ml}$ ). Each sample was injected in triplicate ( $n$ $=3$ ) and obtained peak areas were used to calculate mean and $\%$ RSD values.

Stability studies of the stock solution showed no changes in ivabradine concentrations after $24 \mathrm{~h}$ and $48 \mathrm{~h}$ storage at $4^{\circ} \mathrm{C},-20^{\circ} \mathrm{C}$, and $-80^{\circ} \mathrm{C}$. The mobile phase was also stable under stock solution storage conditions, as well as the analysis conditions.

Limit of detection was determined based on the standard deviation of response (mean SD value of $y$-intercept) and the slope of the calibration curve. The limit of quantification was considered to be three times the limit of detection.

The detection limit was calculated using the method of the signal to noise ratio. Noise was measured at $\pm 0.5 \mathrm{~min}$ from peak start and end for the lowest point from calibration curve. The ratio of signal to noise was determined, and the LOQ was considered to be $3 \times S / N$ while the LOD was $10 \times S / N$.

2.5. Stress Studies. The stress studies were carried out in the same way as described in our previous report [11]. In short, in order to prepare each sample, $1 \mathrm{mg}$ of ivabradine was weighed and dissolved in $2 \mathrm{ml}$ of the appropriate solvent. Thermal degradation was performed by addition of deionised water and storing for $24 \mathrm{~h}$ at $80^{\circ} \mathrm{C}$. For acid and alkaline hydrolysis, $2 \mathrm{~mol} / \mathrm{l} \mathrm{HCl}$ or $1 \mathrm{~mol} / \mathrm{l} \mathrm{NaOH}$ was added to samples and incubated for $24 \mathrm{~h}$ at $80^{\circ} \mathrm{C}$. Studies of possible oxidation products were carried out by adding $3 \% \mathrm{H}_{2} \mathrm{O}_{2}, 7.5 \% \mathrm{H}_{2} \mathrm{O}_{2}$, and $15 \% \mathrm{H}_{2} \mathrm{O}_{2}$ and incubating for $24 \mathrm{~h}$ at $80^{\circ} \mathrm{C}$. Photolytic degradation was performed in solution of deionised water for $24 \mathrm{~h}$ and $48 \mathrm{~h}$ and in solid form for $120 \mathrm{~h}$. The illuminance was set at $500 \mathrm{~W} / \mathrm{m}^{2}$.

\section{Results and Discussion}

3.1. Method Development. In order to determine the best conditions for the analysis, optimisation of the method was performed. In the first step, columns of different properties were investigated: Hypersil Gold C8, $5 \mu \mathrm{m}, 150 \mathrm{~mm} \times 4.6 \mathrm{~mm}$ ID; Zorbax, $5 \mu \mathrm{m}, 150 \mathrm{~mm} \times 4.6 \mathrm{~mm}$ ID; Knauer C8, $5 \mu \mathrm{m}$, $250 \mathrm{~mm} \times 4.6 \mathrm{~mm} \mathrm{ID}$; and Supelco C18, $5 \mu \mathrm{m}, 250 \mathrm{~mm} \times$ 


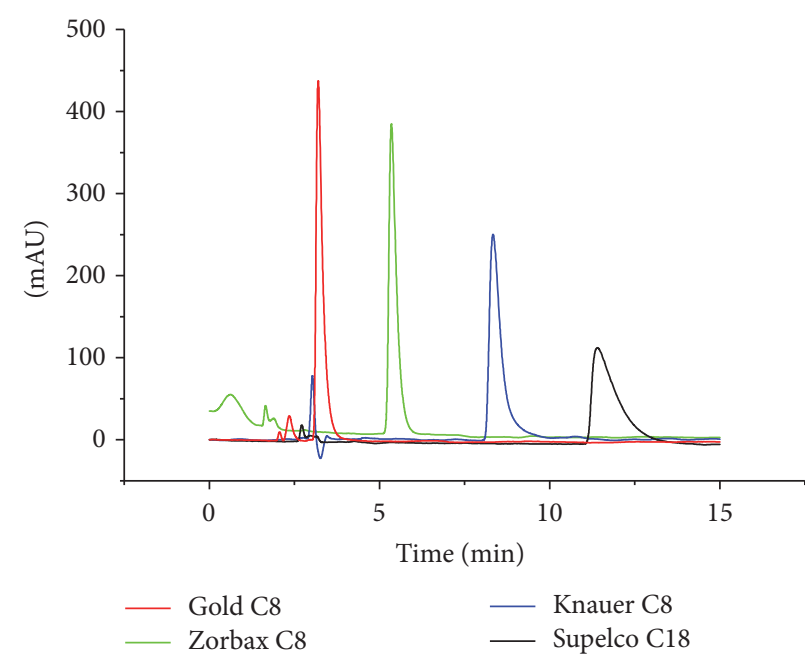

(a)

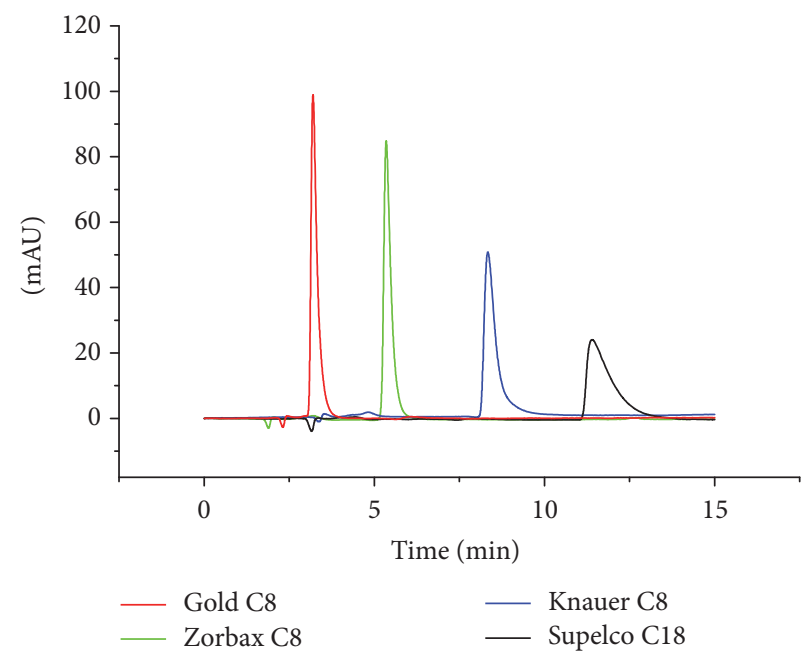

(b)

FIGURE 1: Optimisation of columns for (a) $207 \mathrm{~nm}$ and (b) $286 \mathrm{~nm}$.

TABLE 1: The obtained retention factor, peak asymmetry, and numbers of theoretical plates of investigated columns.

\begin{tabular}{|c|c|c|c|c|c|c|}
\hline & \multicolumn{3}{|c|}{$207 \mathrm{~nm}$} & \multicolumn{3}{|c|}{$286 \mathrm{~nm}$} \\
\hline & $\begin{array}{l}\text { Retention } \\
\text { factor }(k)\end{array}$ & $\begin{array}{c}\text { Peak } \\
\text { asymmetry }\end{array}$ & $\begin{array}{c}\text { Theoretical } \\
\text { plates (HEPT) }\end{array}$ & $\begin{array}{l}\text { Retention } \\
\text { factor }(k)\end{array}$ & $\begin{array}{c}\text { Peak } \\
\text { asymmetry }\end{array}$ & $\begin{array}{c}\text { Theoretical } \\
\text { plates (HEPT) }\end{array}$ \\
\hline Gold C8 & 0.62 & 2.18 & 0.102 & 0.63 & 2.15 & 0.087 \\
\hline Zorbax C8 & 2.57 & 1.89 & 0.050 & 2.01 & 1.82 & 0.044 \\
\hline Knauer C8 & 2.20 & 2.20 & 0.076 & 1.85 & 2.31 & 0.074 \\
\hline Supelco C18 & 3.43 & 3.22 & 0.193 & 2.86 & 3.50 & 0.194 \\
\hline
\end{tabular}

$4.6 \mathrm{~mm}$ ID To choose the most appropriate column, the retention factor, peak asymmetry factor, and height equivalent to a theoretical plate (HETP), as well as the retention time of ivabradine, were taken into consideration (Table 1). The obtained chromatograms are presented in Figure 1. Hypersil Gold C8 was not suitable for ivabradine determination because of the low retention factor (0.62 and 0.63). Supelco C18 was also not suitable due to its high HETP (0.193 and 0.194). The retention time of IVA should be long enough to allow the determination of stress products, which would probably be of lower molecular weight than ivabradine; therefore they would interact less with the column, resulting in a shorter retention time [16]. Both Zorbax C8 and Knauer C8 columns were appropriate for analysis of ivabradine, but it was decided to perform validation on the Knauer C8 column. In the next step, the temperature of the column during analysis was optimised. The results, summarised in Table 2, showed that the temperature has an impact on peak asymmetry. The lowest peak asymmetry was found for the analysis performed with the column oven set to $40^{\circ} \mathrm{C}$. Mobile phase conditions were also optimised; both composition (Figure 2) and flow were examined. The best peak shape was observed for a mobile phase consisting of $40 \%$ acetonitrile and $60 \% 20 \mathrm{mmol}$ ammonium acetate. The
TABLE 2: Peak asymmetry for each temperature and wavelength.

\begin{tabular}{lcc}
\hline & $\begin{array}{c}207 \mathrm{~nm} \\
\text { Peak asymmetry }\end{array}$ & $\begin{array}{c}286 \mathrm{~nm} \\
\text { Peak asymmetry }\end{array}$ \\
\hline $35^{\circ} \mathrm{C}$ & 2.70 & 2.63 \\
$38^{\circ} \mathrm{C}$ & 2.64 & 2.55 \\
$40^{\circ} \mathrm{C}$ & 2.55 & 2.47 \\
\hline
\end{tabular}

highest value of HETP was found for a flow rate of $1 \mathrm{ml} / \mathrm{min}$; for $0.8 \mathrm{ml} / \mathrm{min}$ the HETP was two times lower, and for $1.2 \mathrm{ml} / \mathrm{min}$ it was smaller by nearly $25 \%$. Peak asymmetry was also the lowest for a flow rate of $1 \mathrm{ml} / \mathrm{min}$, regardless of the detection wavelength used.

Finally, validation and analysis of the degradation products were performed on the Knauer C8, $5 \mu \mathrm{m}, 250 \mathrm{~mm} \times$ $4.6 \mathrm{~mm}$ ID column, with $40^{\circ} \mathrm{C}$ oven temperature and a mobile phase composed of $40 \%$ acetonitrile and $60 \% 20 \mathrm{mmol}$ ammonium acetate. The flow rate was $1 \mathrm{ml} / \mathrm{min}$.

3.2. Validation Study. In order to prove the usefulness of the method for the determination of ivabradine, the proposed method was validated. The analytical wavelengths $207 \mathrm{~nm}$ 


\begin{tabular}{|c|c|c|c|c|}
\hline & \multicolumn{2}{|c|}{$207 \mathrm{~nm}$} & \multicolumn{2}{|c|}{$286 \mathrm{~nm}$} \\
\hline & Peak asymmetry & $\begin{array}{c}\text { Theoretical plates } \\
\text { (HETP) }\end{array}$ & Peak asymmetry & $\begin{array}{c}\text { Theoretical plates } \\
\text { (HETP) }\end{array}$ \\
\hline $32 \% \mathrm{ACN}$ & 2.67 & 0.102 & 2.66 & 0.098 \\
\hline $35 \% \mathrm{ACN}$ & 2.71 & 0.096 & 2.73 & 0.092 \\
\hline $40 \% \mathrm{ACN}$ & 2.50 & 0.101 & 2.36 & 0.097 \\
\hline
\end{tabular}

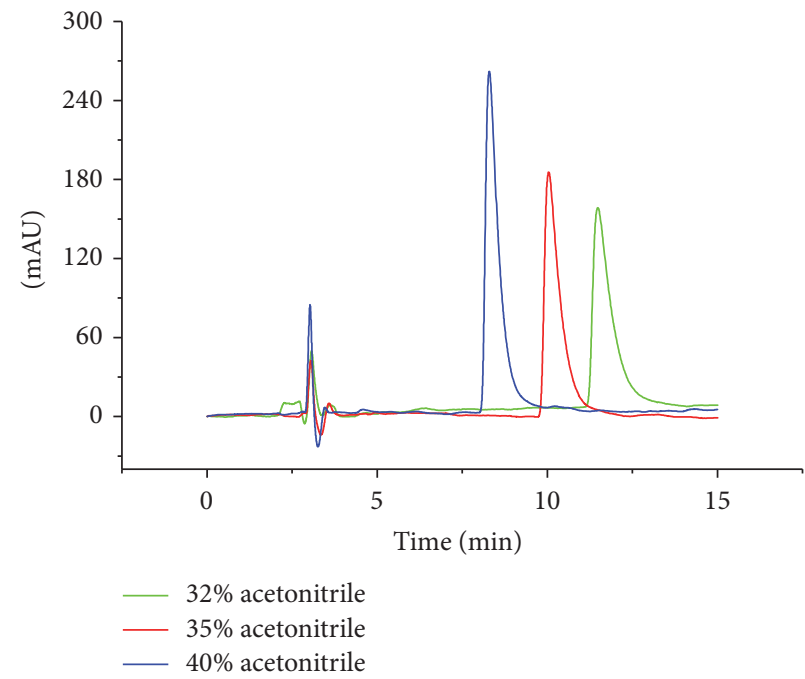

(a)

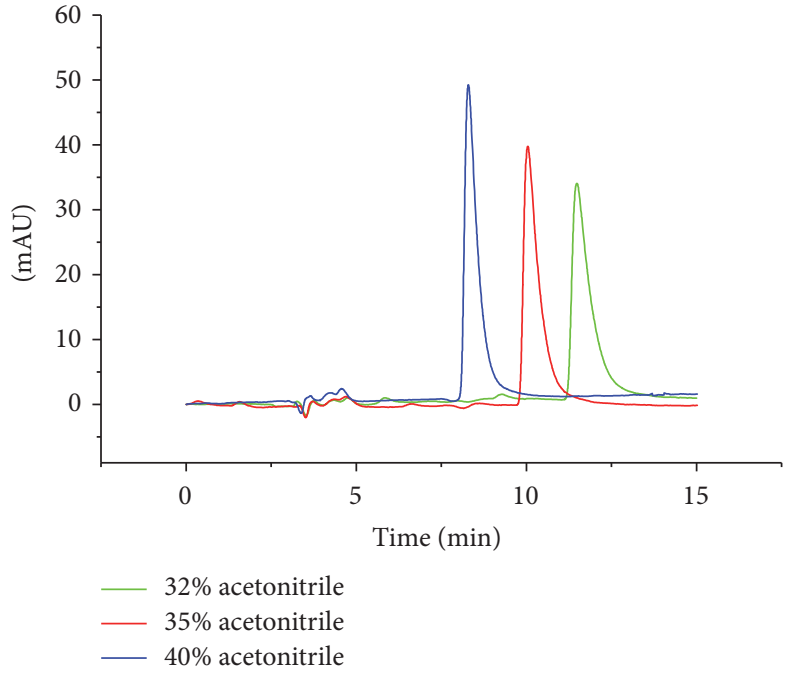

(b)

Figure 2: Optimisation of the mobile phase for the Knauer C8 column for $207 \mathrm{~nm}$ and $286 \mathrm{~nm}$, with information about peak asymmetry and height equivalent to a theoretical plate, for various amounts of acetonitrile in the mobile phase.

TABLE 3: Validation parameters of proposed method.

\begin{tabular}{lcc}
\hline Parameter & $207 \mathrm{~nm}$ & $286 \mathrm{~nm}$ \\
\hline Linear work range $[\mu \mathrm{g} / \mathrm{ml}]$ & $5-100$ & $5-100$ \\
Slope \pm SD & $1.3286 \pm 0.110$ & $0.2544 \pm 0.001$ \\
Intercept \pm SD & $-0.3355 \pm 0.277$ & $0.0659 \pm 0.012$ \\
Coefficient of correlation $(r)$ & 0.9990 & 0.9993 \\
Limit of detection (LOD) $[\mu \mathrm{g} / \mathrm{ml}]$ & 0.33 \\
Limit of quantification $(\mathrm{LOQ})[\mu \mathrm{g} / \mathrm{ml}]$ & 1.09 \\
Intra-assay precision $1 \% \mathrm{RSD}, n=6 ; 10 \mu \mathrm{g} / \mathrm{ml})$ & 5.97 \\
Intra-assay precision $2(\% \mathrm{RSD}, n=6 ; 50 \mu \mathrm{g} / \mathrm{ml})$ & 5.81 \\
Intra-assay precision $3(\% \mathrm{RSD}, n=6 ; 100 \mu \mathrm{g} / \mathrm{ml})$ & 6.80 \\
Interassay precision $(\% \mathrm{RSD}, n=3 ; 10 \mu \mathrm{g} / \mathrm{ml})$ & 3.44 \\
Recovery $(\%, n=3)$ & $92.1-102.2$ & 3.97 \\
\hline
\end{tabular}

Intra-assay precision concentrations were 10,50 , and $100 \mu \mathrm{g} / \mathrm{ml}$, respectively.

and $286 \mathrm{~nm}$ were selected, since ivabradine has two absorption maxima. It was decided to use both wavelengths for HPLC validation due to the fact that the molar absorption coefficient $(\varepsilon)$ for $207 \mathrm{~nm}$ is over six times higher than that for $286 \mathrm{~nm}$. As a result, the peak areas at $207 \mathrm{~nm}$ were considerably higher, which led to improvement in limit of detection (LOD) and limit of quantification (LOQ) values.

During the validation, it has been recommended to use wavelengths longer than $240 \mathrm{~nm}$ [17]. The use of wavelengths less than $240 \mathrm{~nm}$ is associated with detection of impurities instead of the analysed compound, but in this case, the use of a short wavelength in the UV range is desirable, since the purpose is conducting the degradation studies. Such an approach increases the probability of detection of degradation products (unknown compounds). As previously shown, ivabradine has two chromophore groups that absorb light in the UV-Vis region, and it is not known which group will be eliminated or changed in the process of degradation, so it was decided to use both mentioned wavelengths [18].

Regression coefficients of the calibration curves, as well as limits of detection and quantification, are shown in Table 3. The method of determination LOQ and LOD based on the 


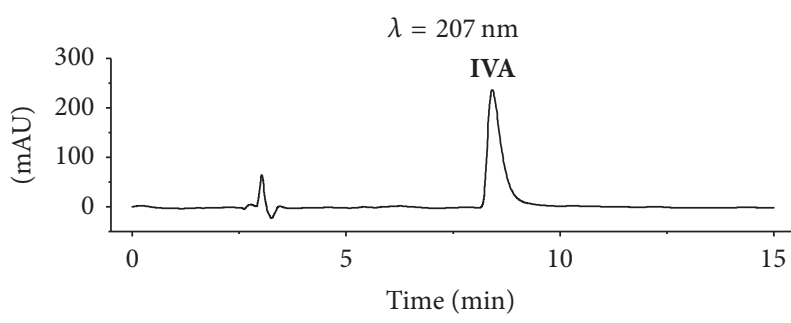

(a)

$\lambda=207 \mathrm{~nm}$

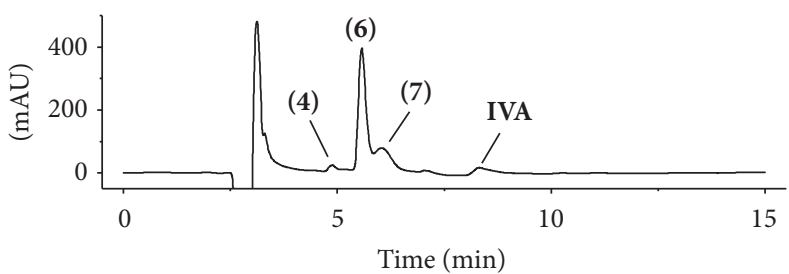

(c)

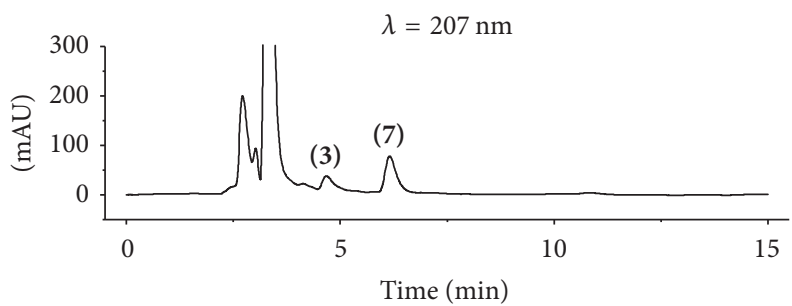

(e)

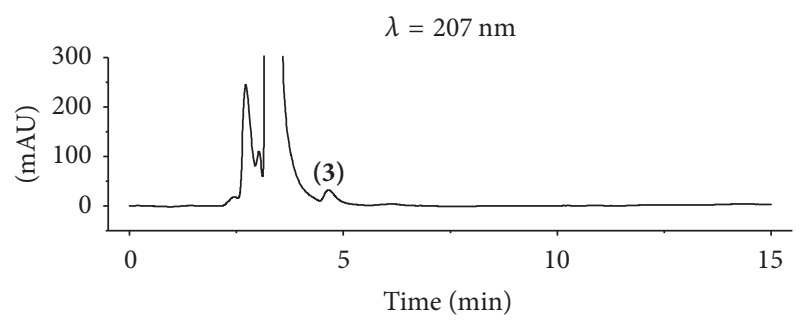

(g)

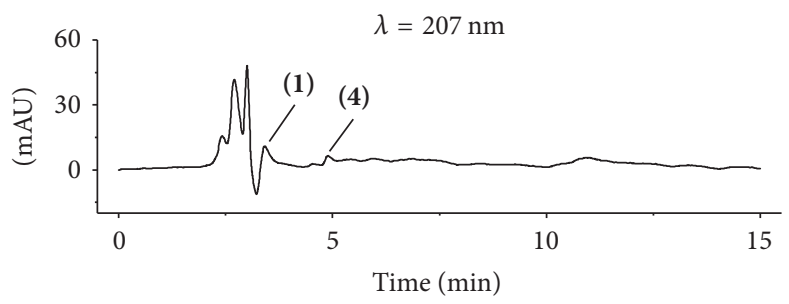

(i)

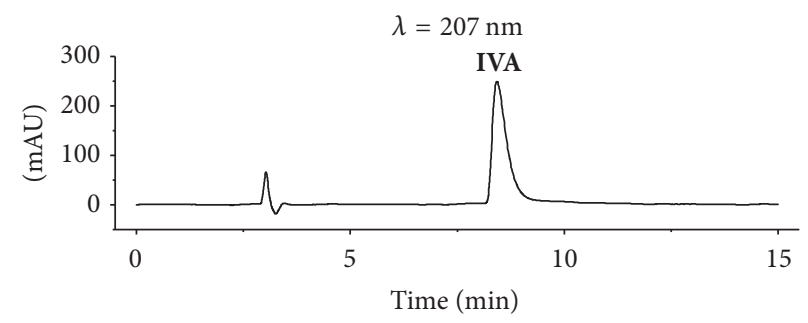

(b)

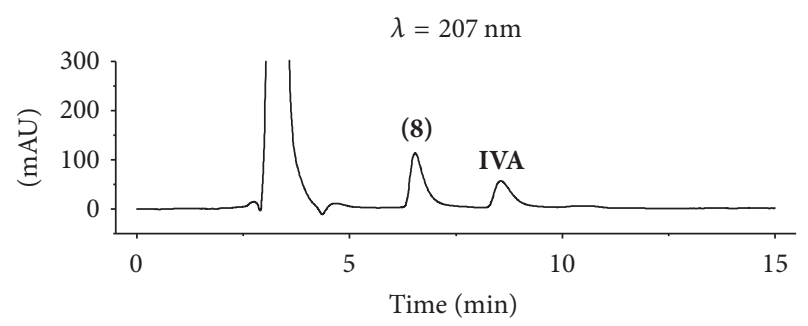

(d)

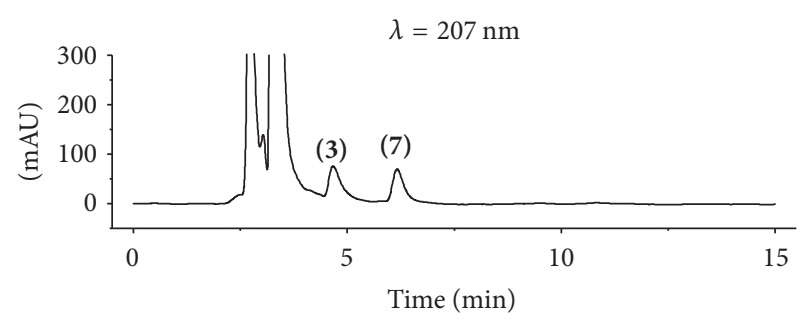

(f)

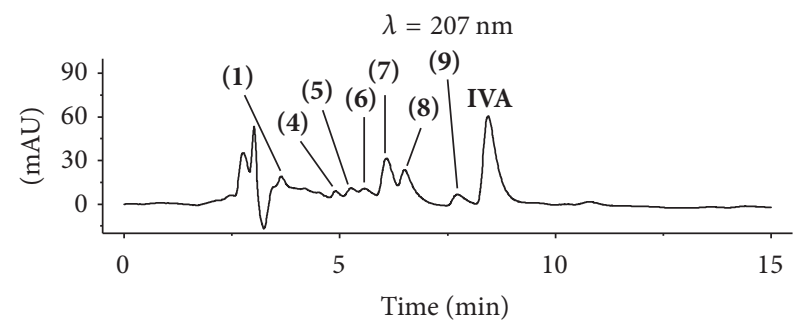

(h)

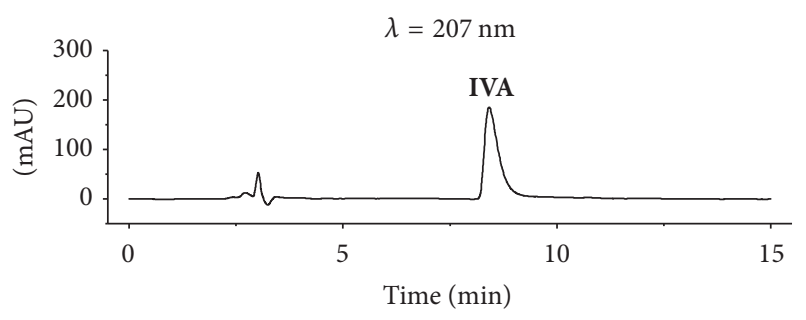

(j)

FIGURE 3: Chromatographic set showing degradation products generated in various conditions at $207 \mathrm{~nm}$ : (a) thermal degradation (solution), (b) thermal degradation (powder), (c) acid degradation, (d) alkaline degradation, (e) oxidation $\left(3 \% \mathrm{H}_{2} \mathrm{O}_{2}\right),(\mathrm{f})$ oxidation $\left(7.5 \% \mathrm{H}_{2} \mathrm{O}_{2}\right),(\mathrm{g})$ oxidation $\left(15 \% \mathrm{H}_{2} \mathrm{O}_{2}\right)$, (h) photolysis $(24 \mathrm{~h})$, (i) photolysis $(48 \mathrm{~h})$, and $(\mathrm{j})$ photolysis (powder, $\left.120 \mathrm{~h}\right)$.

$S / N$ ratio is consistent with the standard deviation of the $y$-intercept of the calibration curve method, since both give similar results.

Comparing validation parameters of the available methods of ivabradine determination to the UV-Vis detection method, this research had shown wider linearity range than
Maheshwari et al., who designated linearity for $286 \mathrm{~nm}$ [16]. LOQ and LOD were proved to be very low [16]. However, the wider linearity range for $285 \mathrm{~nm}$ was reported in the work by Rahman et al. [19]. A better indirect precision was acquired, probably because of significantly higher concentrations of analyte used [19]. In the research, a wider linearity range 


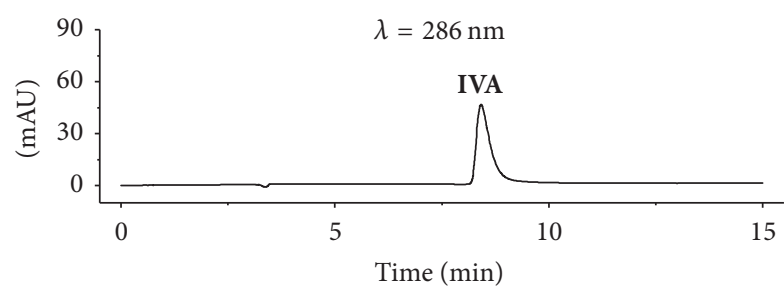

(a)

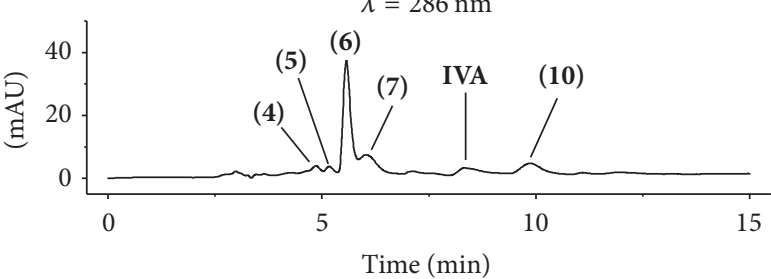

(c)

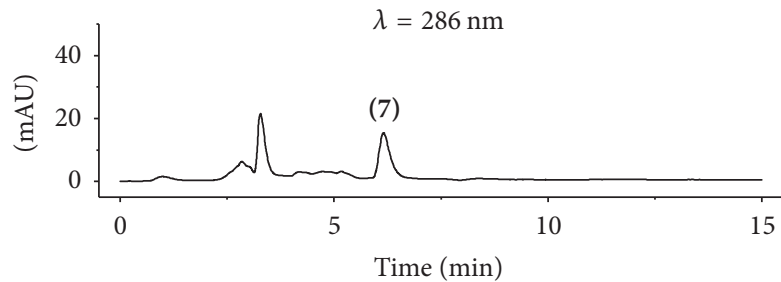

(e)

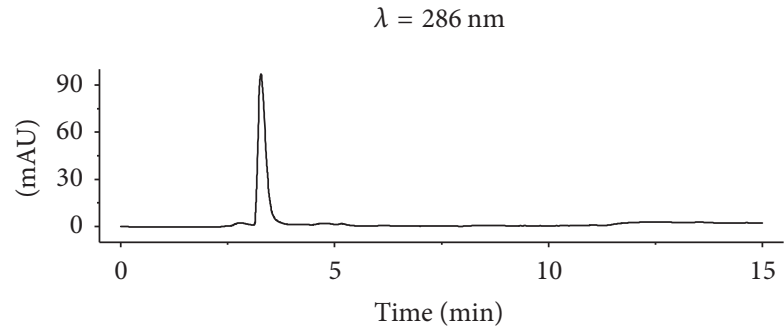

(g)

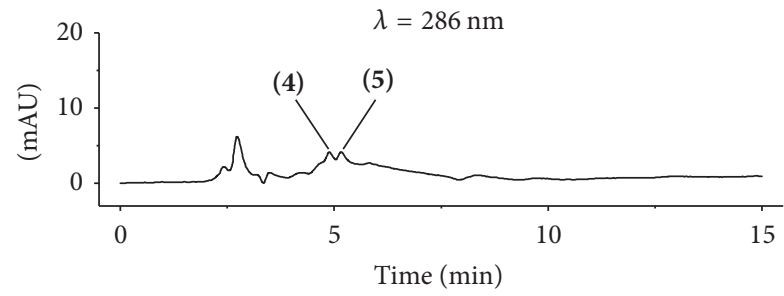

(i)

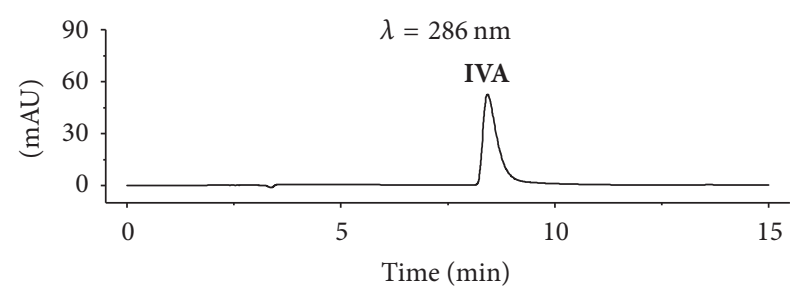

(b)

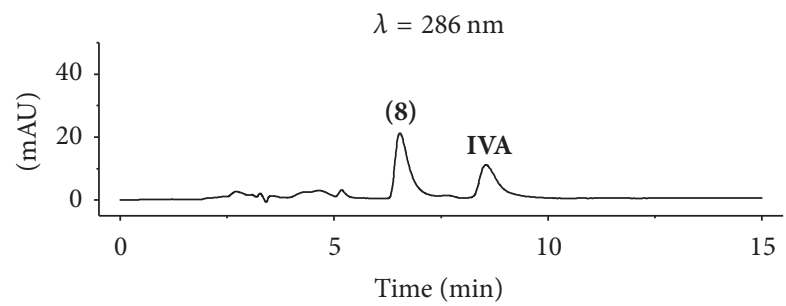

(d)

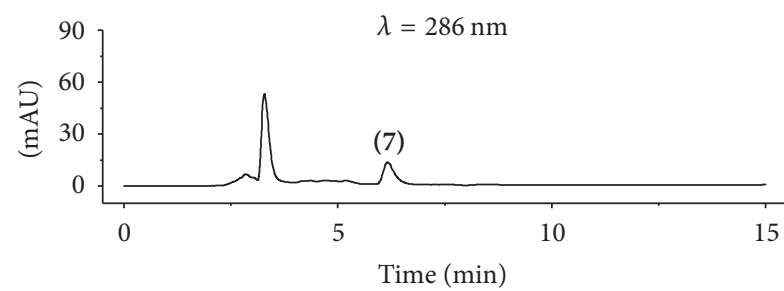

(f)

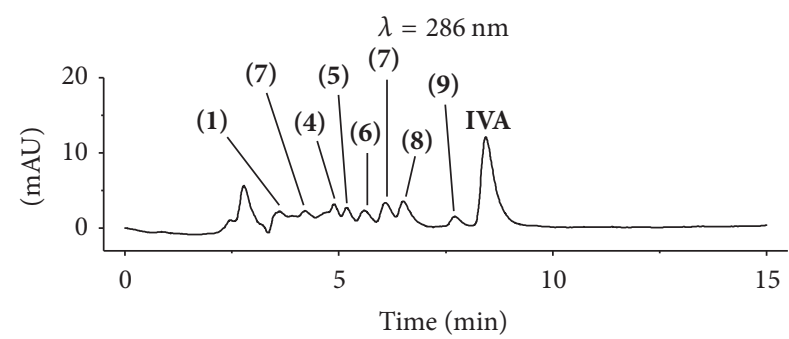

(h)

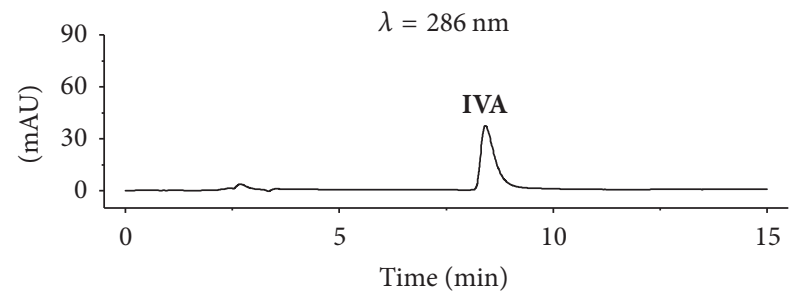

(j)

FIGURE 4: Chromatographic set showing degradation products generated in various conditions at $286 \mathrm{~nm}$ : (a) thermal degradation (solution), (b) thermal degradation (powder), (c) acid degradation, (d) alkaline degradation, (e) oxidation $\left(3 \% \mathrm{H}_{2} \mathrm{O}_{2}\right),(\mathrm{f})$ oxidation $\left(7.5 \% \mathrm{H}_{2} \mathrm{O}_{2}\right),(\mathrm{g})$ oxidation $\left(15 \% \mathrm{H}_{2} \mathrm{O}_{2}\right)$, (h) photolysis $(24 \mathrm{~h})$, (i) photolysis $(48 \mathrm{~h})$, and $(\mathrm{j})$ photolysis (powder, $\left.120 \mathrm{~h}\right)$.

was acquired compared to that in the research carried out by Maheshwari et al. as well as a smaller range than that shown in the paper by Rahman et al. $[16,19]$. In both papers, the authors do not mention the method of calculating LOQ and LOD; therefore, it is impossible to compare these values. In both studies retention time did not differ significantly from that obtained in this study.
3.3. Application of Validated Method on Degradation Study. Our previous study discussed widely the stress degradation process of ivabradine. The study was performed with the use of LC-MS/MS apparatus. Generally, LC-MS/MS technology is becoming more popular, but LC-UV/DAD is still the common standard. LC-UV/DAD provides a relatively low cost of maintenance and depreciation of equipment, in comparison 
to LC-MS/MS. For this reason, we decided to transfer our method to LC-UV/DAD apparatus. We managed to achieve equally good separation of ivabradine from its degradation products as those described by us in the previous work [11]. Briefly, the largest numbers of degradation products were found in samples exposed to $24 \mathrm{~h}$ radiation (eight products) and alkaline hydrolysis (six products). Chromatograms showing ivabradine degradation products are presented in Figures 3 and 4.

The most important aspect is the fact that method could be used for simple separation, as well as detection, of degradation products obtained. From a practical point of view, the UV-DAD detector is widely available for controlling the degradation products of ivabradine in the pharmaceutical industry.

\section{Conclusion}

A simple isocratic RP-HPLC method for determination of ivabradine and its degradation products was successfully validated. The studies showed that $207 \mathrm{~nm}$ meets the conditions required for analytical wavelength. The proposed method is suitable for the determination of ivabradine and its degradation products and could be successfully implemented in quality control and routine analysis of pharmaceutical dosage forms. Various degradation products were obtained, but it can be stated that ivabradine is a stable chemical compound, especially in solid form, from which no degradation products were obtained.

\section{Conflicts of Interest}

The authors declare that they have no conflicts of interest.

\section{References}

[1] S. Sulfi and A. D. Timmis, "Ivabradine-the first selective sinus node If channel inhibitor in the treatment of stable angina," International Journal of Clinical Practice, vol. 60, no. 2, pp. 222228, 2006.

[2] K. Fox, I. Ford, P. G. Steg, M. Tendera, and R. Ferrari, "Ivabradine for patients with stable coronary artery disease and leftventricular systolic dysfunction (BEAUTIFUL): a randomised, double-blind, placebo-controlled trial," The Lancet, vol. 372, no. 9641, pp. 807-816, 2008.

[3] K. Swedberg, M. Komajda, M. Böhm et al., "Ivabradine and outcomes in chronic heart failure (SHIFT): a randomised placebocontrolled study," The Lancet, vol. 376, no. 9744, pp. 875-885, 2010.

[4] D. Difrancesco, "The role of the funny current in pacemaker activity," Circulation Research, vol. 106, no. 3, pp. 434-446, 2010.

[5] C. Wahl-Schott and M. Biel, "HCN channels: Structure, cellular regulation and physiological function," Cellular and Molecular Life Sciences, vol. 66, no. 3, pp. 470-494, 2009.

[6] A. Ludwig, X. Zong, J. Stieber, R. Hullin, F. Hofmann, and M. Biel, "Two pacemaker channels from human heart with profoundly different activation kinetics," EMBO Journal, vol. 18, no. 9, pp. 2323-2329, 1999.

[7] P. Pikul, J. Nowakowska, and K. Ciura, "Effect of non-aqueous and buffered mobile-phase composition on the retention of ivabradine," Journal of Liquid Chromatography and Related Technologies, vol. 37, no. 13, pp. 1837-1846, 2014.

[8] P. Pikul, J. Nowakowska, and K. Ciura, "Chromatographic analysis of ivabradine on polar, nonpolar and chemically modified adsorbents by HPTLC," Journal of Food and Drug Analysis, vol. 21, no. 2, pp. 165-168, 2013.

[9] P. Klippert, J.-P. Jeanniot, S. Polvé, C. Lefèvre, and H. Merdjan, "Determination of ivabradine and its $\mathrm{N}$-demethylated metabolite in human plasma and urine, and in rat and dog plasma by a validated high-performance liquid chromatographic method with fluorescence detection," Journal of Chromatography B: Biomedical Applications, vol. 719, no. 1-2, pp. 125-133, 1998.

[10] M. François-Bouchard, G. Simonin, M.-J. Bossant, and C. Boursier-Neyret, "Simultaneous determination of ivabradine and its metabolites in human plasma by liquid chromatographytandem mass spectrometry," Journal of Chromatography B: Biomedical Sciences and Applications, vol. 745, no. 2, pp. 261269, 2000.

[11] P. Pikul, M. Jamrógiewicz, J. Nowakowska, W. Hewelt-Belka, and K. Ciura, "Forced degradation studies of ivabradine and in silico toxicology predictions for its new designated impurities," Frontiers in Pharmacology, vol. 7, no. MAY, article no. 117, 2016.

[12] L. Vlase, D. Muntean, S. E. Leucuţa, and I. Bâldea, "Highthroughput determination of ivabradine from human plasma by LC/MS/MS and its application to pharmacokinetic studies," Studia Universitatis Babes-Bolyai Chemia, vol. 2, pp. 43-52, 2009.

[13] J. Jiang, L. Tian, Y. Huang, and Y. Li, "Development and validation of a sensitive LC-MS/MS-ESI method for the determination of ivabradine in human plasma: Application to a pharmacokinetic study," Biomedical Chromatography, vol. 27, no. 12, pp. 1603-1608, 2013.

[14] P. N. Patel, R. M. Borkar, P. D. Kalariya et al., "Characterization of degradation products of Ivabradine by LC-HR-MS/MS: A typical case of exhibition of different degradation behaviour in $\mathrm{HCl}$ and $\mathrm{H} 2 \mathrm{SO} 4$ acid hydrolysis," Journal of Mass Spectrometry, vol. 50, no. 2, pp. 344-353, 2015.

[15] M. H. Motisariya, K. G. Patel, and P. A. Shah, "Validated stability-indicating high performance thin layer chromatographic method for determination of Ivabradine hydrochloride in bulk and marketed formulation: an application to kinetic study," Bulletin of Faculty of Pharmacy, Cairo University, vol. 51, no. 2, pp. 233-241, 2013.

[16] S. Maheshwari, A. P. Khandhar, and A. Jain, "Quantitative Determination and Validation of Ivabradine HCL by Stability Indicating RP-HPLC Method and Spectrophotometric Method in Solid Dosage Form," Eurasian Journal of Analytical Chemistry, vol. 5, no. 1, pp. 53-62, 2010.

[17] L. R. Snyder, J. J. Kirkland, and J. L. Glajch, Practical HPLC Method Development, John Wiley Sons, New York, 2nd edition, 1988.

[18] A. Synak, P. Pikul, P. Bojarski et al., "Transition moment directions and selected spectroscopic properties of Ivabradine," Spectrochimica Acta - Part A: Molecular and Biomolecular Spectroscopy, vol. 101, pp. 162-166, 2013.

[19] M. R. Rahman, M. Asaduzzaman, and S. M. A. Islam, "Development and validation of RP-HPLC method for analysis of Ivabradine hydrochloride in tablet dosage forms," Research Journal of Pharmaceutical, Biological and Chemical Sciences, vol. 3, no. 3, pp. 1032-1043, 2012. 

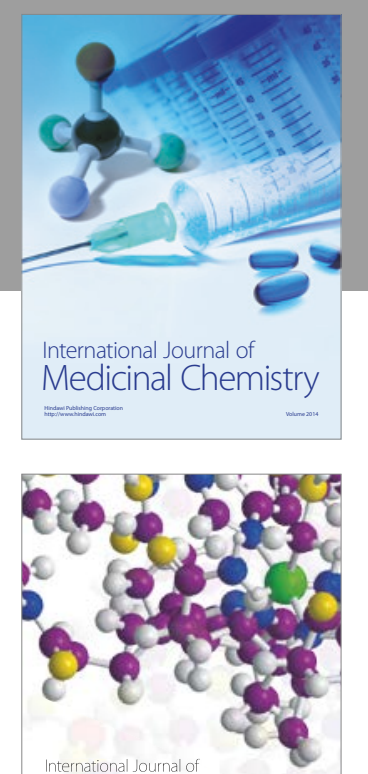

Carbohydrate Chemistry

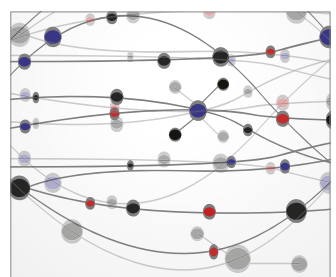

The Scientific World Journal
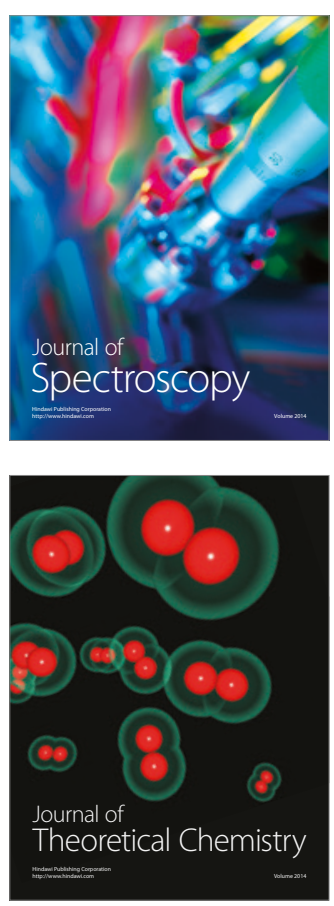
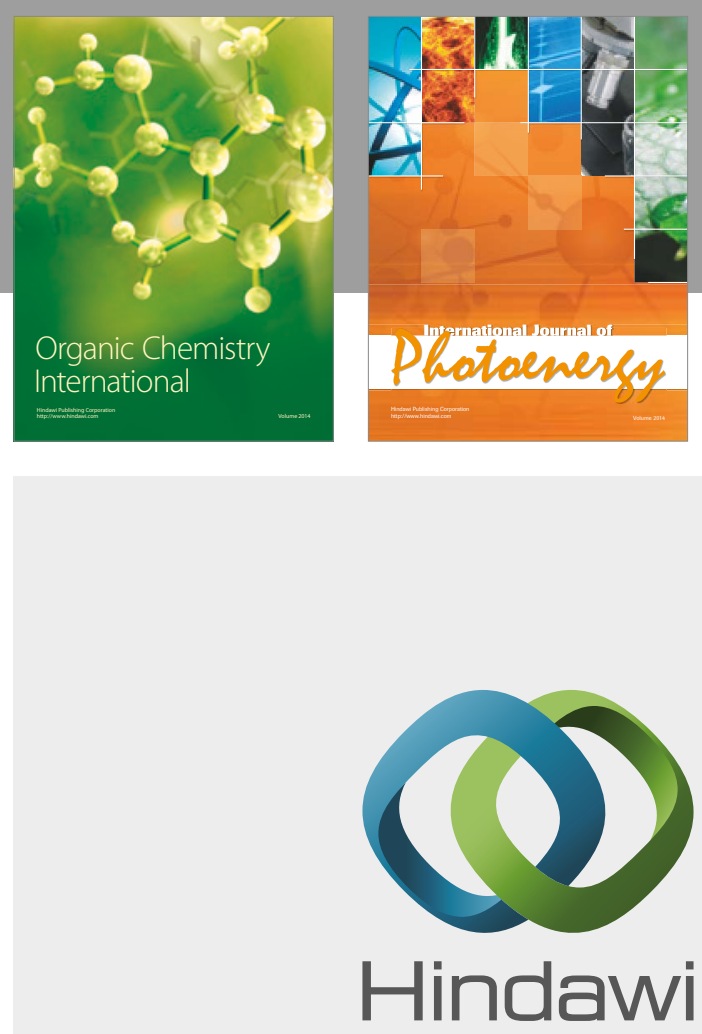

Submit your manuscripts at

https://www.hindawi.com

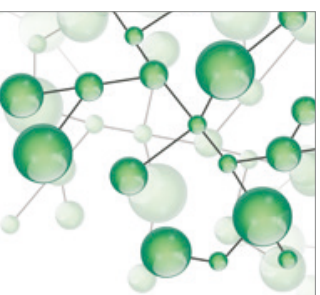

International Journal of

Inorganic Chemistry

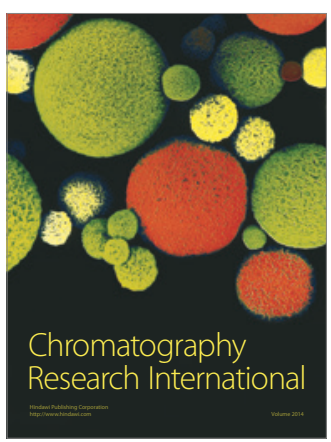

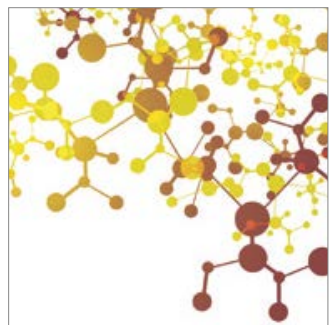

Applied Chemistry
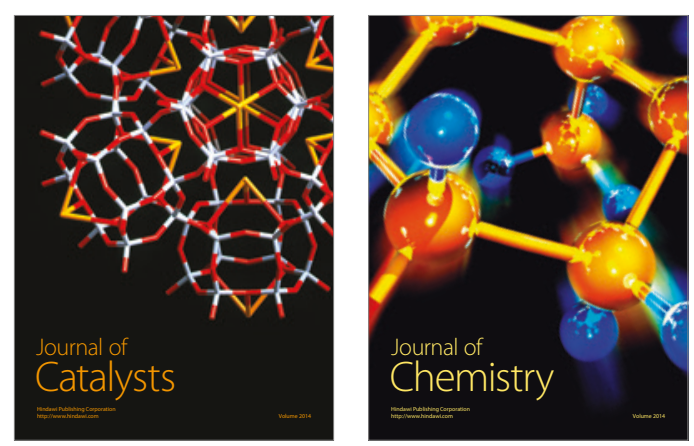
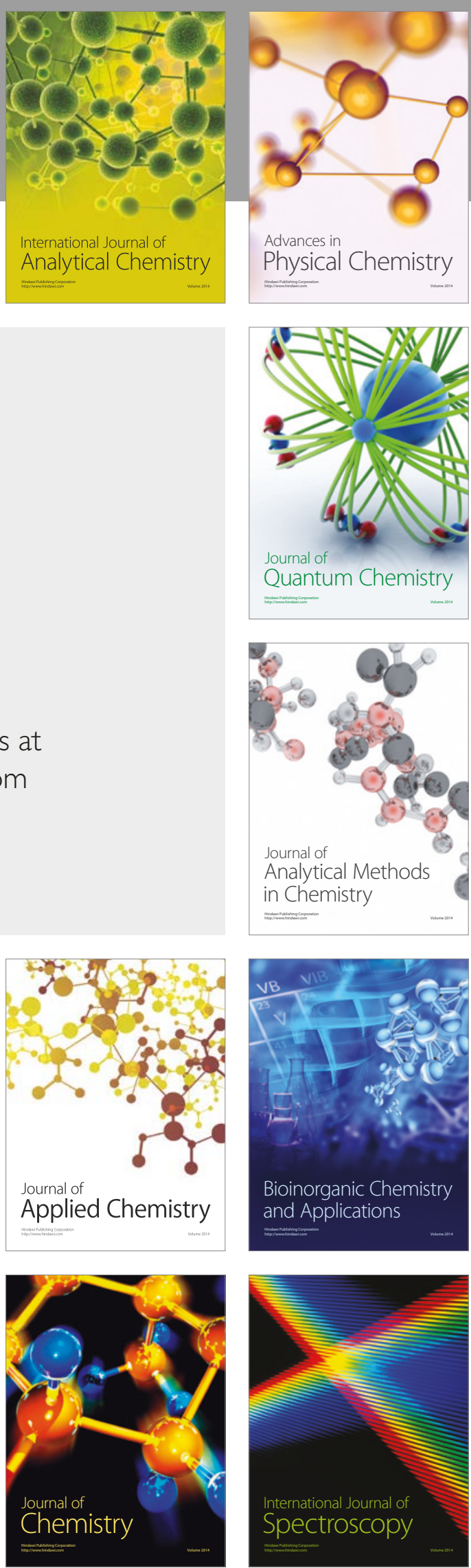